\title{
Modelling of Alkali Silica Reaction in concrete structures for rehabilitation intervention
}

\author{
Mohammad S. Pourbehi ${ }^{1, *}$, G.P.A.G. van Zij1 ${ }^{1}$, and J.A.v.B. Strasheim ${ }^{1}$ \\ ${ }^{1}$ Division for Structural Engineering and Civil Engineering Informatics, Stellenbosch University, South Africa
}

\begin{abstract}
A number of hydraulic structures such as dams and hydro-power plants in the world and in particular, in South Africa which have been designed and built during the last decades, have been subjected to material deterioration due to Alkali Silica Reaction (ASR). ASR is a deleterious chemical reaction between the alkalis in Portland cement paste and certain amorphous silica found in various types of natural aggregates which usually results in material degradation and structural distress such as expansion of the structure, cracking, presence of gel, discoloration and pop outs of the reacting particles near the surface of the concrete. Also, suitable environmental conditions (temperature and relative humidity) play a vital role in the initiation and advancement of ASR. In this study a chemo-thermo-mechanical model is developed to predict the structural expansion, degradation of mechanical properties, cracks and damage in concrete structures affected by ASR. Parameters such as temperature, kinetics of the reaction, confining stresses and material degradation are included in the model. The finite element based model can simulate the temperature field in the structure and the kinetics of the chemical reaction to predict the long-term effects of the ASR on concrete structures including displacement, cracking and damage development. The model is applied to an actual concrete dam subjected to ASR. The results are interpreted, and support the management and evaluation of the remedial measures for repair and maintenance programmes for the affected dams.
\end{abstract}

\section{Introduction}

Alkali-Silica reaction is a deleterious chemical reaction between alkalis in Portland cement paste and certain amorphous silica in a variety of natural aggregates. Numerous concrete structures, such as dams and bridges and more recently nuclear power plants, have been suffering from deterioration due to ASR. This problem was first reported by Stanton [1] in the USA and in South Africa the problem was first identified in structures in the Cape Peninsula in the 1970s [2]. Since then, many efforts have been made to investigate the ASR on the material and structural scales, including the physical chemistry of ASR, laboratory work such as accelerated test methods, expansion mechanism and structural response to ASR effects, and ASR management and reduction measures [3]. A list of reported cases of dams and hydraulics structures affected by ASR in South Africa can be found in [4].

The chemistry of ASR is multi-staged and complex and is essentially an acid base one. Alkalis are present in Portland cement in the form of the Alkali-silicate or Alkali-aluminate. Among these, sulphates acting as a counter ion of the alkali in the pore solution at earliest stage of the cement hydration are dominant. When the process of precipitation of Ettringite is completed, the counter ions of the alkalis become hydroxides. Evidence exists that an increase in the $\mathrm{pH}$ of the pore solution is caused by both alkali ions $\left(\mathrm{Na}^{+} \mathrm{K}^{+}\right)$and hydroxide ions
$\left(\mathrm{OH}^{-}\right)$concentrating at a sufficiently high level. See Fig. 1 . Due to this process the ions are ready to attack the noncrystalline silicon di-oxide (silica) which is found in many common aggregates to form alkali-silica gel. This gel is highly hydrophilic and in the presence of water expands. Initially, the gels fill the pores and micro cracks available in cement and interfacial transition zone (ITZ) and further expansion induces a build-up of internal pressure which is the main mechanism of the swelling and degradation of elastic properties in material scale.

However, on structural scale, ASR leading to damage and deterioration of structures mainly depends on different coexistence conducive factors. Three vital factors are: (i) the presence of potentially reactive silica in critical proportion. (ii) Sufficiently high alkali hydroxide concentration to trigger and sustain reaction (iii) available water to initiate the reaction and then drive the swelling of the gel [5].

It is now widely accepted that the water ingress by the gel and resulting swelling, is the main reason for concrete expansion and deterioration of ASR affected structures. The swelling of gel creates an increasing internal pressure, causing the opening and propagation of cracks when the tensile strength of the concrete skeleton is exceeded. Recently, experimental programmes have been conducted to explain the mechanism of expansion and cracking on material scale and structural level by ASR due to the fact that this mechanism is still not clearly understood.

\footnotetext{
* Corresponding author: $\underline{\text { mpourbehi@sun.ac.za }}$
} 


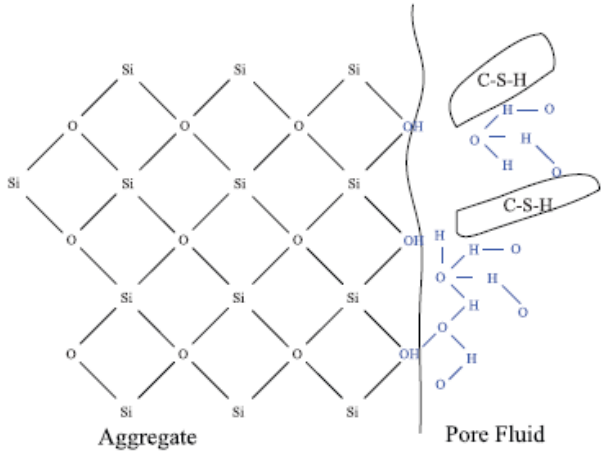

Fig. 1. Aggregate-cement paste interface. Aggregate is attacked by alkali hydroxyls ions [6].

ASR affects many concrete structures and causes permanent deformation and cracking, which reduces the durability and safety of the structures. Modelling is required to analyse the behaviour of ASR-affected structures, thus evaluating the safety level and long term performance of structures suffering from ASR. In general, mathematical models for modelling ASR and its effects fall into three main categories: (1) macrostructural models concerned with the analysis of structures affected by the reaction [Charlwood et. al. [7], Ulm et al [8], Capra and Sellier [9], Saouma and Perotti [10]]; (2) microstructural models which aim to link the chemical process of the reaction to its impact at the material level $[11,12]$; (3) mesoscopic models $[13,14]$. These mesoscopic models take into account the multiphase nature of the aggregate, cement paste, void and ASR gel, thus anisotropy can be explicitly represented in the concrete material model. ASR can be described as two simultaneous but uncoupled processes: The production of expansive silica gel, and its mechanical consequences. The mechanical stress can affect both of these processes. Indeed, some chemical reactions and dissolution processes are known to be hindered or promoted by external pressure. However, the results from Larive [15] indicate that such phenomena do not occur in ASR, at least in the range of stresses encountered in the field. To the contrary, in a recent experimental research by Liaudat et al [16], it has been shown that a $3 \mathrm{D}$ state of permanent stress equal to -9.7 $\mathrm{MPa}$ can hinder the volumetric ASR strains. Mechanical loads also affect the fracture processes in the material, and therefore the expansion as it is, in ASR, may be strongly coupled with internal damage [17]. Several factors may significantly control the ASR process and the effects on the mechanical properties of concrete. Experimental campaigns [15, 18, 19] confirm that the water and temperature are two of the key factors that have a strong influence on the reaction kinetics. Thus numerical modelling should be able to capture the impact of humidity, temperature, reactivity of silica and confining stresses as the most prominent factors. Due to the complexity of developing a comprehensive model that captures realistic response of structures, based on the present qualitative knowledge about the ASR chemistry, theoretical, analytical, numerical and semi-empirical models have been mainly developed, based on the observed response of ASR-affected concrete at a material scale or a structural scale.
Modelling approaches in literature have represented ASR swelling by equivalent thermal expansion [7]. If these approaches do not also incorporate thermal dependence of the ASR process, global response might be represented with reasonable accuracy, but local effects like cracking, and long term behaviour of dam structures may not be predicted correctly. In this research a chemothermo-damage-plastic model considering the strain from ASR and thermal variation which is coupled with material degradation is explored in order to assess the safety level of ASR-affected dam structure. The effect of 3D stress confinement in ASR evolution is modelled using a user subroutine developed for the Abaqus FE software package [20].

The proposed model is first calibrated and validated on material scale on the basis of experimental data provided by accelerated tests which are documented in the literature [18]. Then the model is validated by modelling the mechanical response of the Fontana gravity dam and comparing the results with the actual data on macrocracks appearance and crest displacements reported by Ingraffea [21] and others numerical models available in literature. This is a well-known case history in dam engineering as a highly affected dam by ASR on material and structural level. Since the ASR kinetics is strongly coupled with the temperature variation in massive concrete structures such as dams, the cyclic temperature fields within the dam are computed preliminary. In doing so, the proposed model with a plastic damage mechanical model is assumed to be coupled only in one direction with the preliminary thermal analysis.

Finally, the results are interpreted, and support the management and evaluation of the remedial measures for repair and maintenance programmes for the affected dams.

\section{Chemo-mechanical modelling}

Currently, no practical methods to cease the swelling chemical reaction in concrete dams such as ASR are identified. Therefore, engineers must develop a numerical model that can predict the long-term behaviour of the structure to justify the potential damage and to properly plan the rehabilitation and remedial action. In this research a chemo-mechanical model is developed to predict the structural expansion, degradation of mechanical properties, cracks and damage in concrete structures affected by ASR. Parameters such as temperature, kinetics of the reaction and confining stresses, are included in the model. The finite element based model can simulate the temperature field in the structure and the kinetics of the chemical reaction to predict the long-term effects of the ASR on concrete structures including displacement, cracking and damage development.

\subsection{ASR modelling}

In continuum mechanics one can read the total strain as a superposition of strains from different mechanisms involved in the medium such as: 


$$
\dot{\varepsilon}=\dot{\varepsilon}^{e l}+\dot{\varepsilon}^{p l}+\dot{\varepsilon}^{t h}+\dot{\varepsilon}^{a s r}
$$

Where: $\dot{\boldsymbol{\varepsilon}}^{\boldsymbol{a} \boldsymbol{} \boldsymbol{s}}$ is ASR strain rate in each principal direction according to equation (2). $\dot{\varepsilon}^{\text {th }}$ is thermal strain rate and $\dot{\varepsilon}^{p l}$ is plastic strain rate and $\dot{\varepsilon}^{e l}$ is elastic strain rate. These terms will be defined in detail next.

In this paper, it is assumed that strain from ASR is volumetric in free stress expansions. This assumption is considered by many researchers and experimental works demonstrated a reasonable agreement with numerical models considering volumetric strain $[10,18]$. In recent experiments by Liaduat et al. [16], an ad-hoc device is introduced which is able to apply triaxial loads on ASR specimens for a long period. The results indicate that the ASR expansion is volumetric in free stress state tests and transfers to the less compressed direction. Also, they observed that a triaxial stress state equal to $-9.7 \mathrm{MPa}$ could hinder the volumetric strain rate. Therefore, the expansion from ASR strains in each principal direction can be defined by a rate form which is suitable for integration:

$$
\dot{\varepsilon}_{i}^{a s r}=\Gamma_{c}\left(\sigma_{v}\right) \dot{\xi}\left[\tau_{L}\left(\theta, \sigma_{v}, f_{c}^{\prime}\right), \tau_{c}(\theta)\right] \beta W_{i}\left(\sigma_{v}\right)
$$

In this equation $\xi \in[0,1]$ is kinetics of the chemical reaction. In 1998, an extensive laboratory research in LCPC-France by Larive [15] led to the development of the most promising kinetics. This variable in rate form is:

$$
\dot{\xi}=\frac{e^{t / \tau_{c}}\left(e^{\tau_{l} / \tau_{c}}+1\right)}{\tau_{c}\left(e^{t / \tau_{c}}+e^{\tau_{c} / \tau_{l}}\right)^{2}}
$$

Where $\tau_{l}$ and $\tau_{c}$ are the latency and characteristic times respectively. Time $\tau_{c}$ and $\tau_{L}$ can be estimated using an Arrhenius relation:

$$
\begin{gathered}
\tau_{c}(\theta)=\tau_{c}\left(\theta_{0}\right) \exp \left[U_{c}\left(1 / \theta-1 / \bar{\theta}_{0}\right)\right], \\
\tau_{L}\left(\theta, \sigma_{v}, f_{c}^{\prime}\right)=f\left(\sigma_{v}, f_{c}^{\prime}\right) \tau_{L}\left(\theta_{0}\right) \exp \left[U_{L}\left(1 / \theta-1 / \bar{\theta}_{0}\right)\right]
\end{gathered}
$$

The latency time and characteristic time are functions of the current temperature $\theta$ and the temperature $\bar{\theta}_{0}$ which iso-thermal laboratory tests have been conducted for their identification [15].

$$
f\left(\sigma_{v}, f_{c}^{\prime}\right)=\left\{\begin{array}{cc}
1 & \sigma_{v}>0 \\
1+\alpha \frac{\sigma_{v}}{3 f_{c}^{\prime}} & \sigma_{v} \leq 0
\end{array}\right.
$$

Function (5) is a retardation function that considers the increase in latency time due to this fact that microcracks relevant to volumetric compressive stresses could likely absorb some gel which is produced during the chemical reaction. This mechanism could delay the ASR initiation [10].

In addition, in equation (4) $U_{c}$ and $U_{L}$ are activation energy constants in Kelvin $(K)$ and are defined as:

$$
U_{c}=5400 \pm 500 \mathrm{~K}
$$

$$
U_{L}=9400 \pm 500 \mathrm{~K}
$$

Furthermore, $\beta$ is asymptotic volumetric expansion strain in the stress-free experiment and depends on the type of aggregates and the other mix proportion parameters as well as on the moisture content. ASR can be confined through different constraints. The forces from these constraints may be caused by the permanent loads such as gravity forces or imposed loads such as hydrostatics loads in a reservoir. Also the forces may arise due to ASR expansion itself, as the expansion of the concrete faces a reaction from boundary conditions. The confinement forces that are created by the swelling of the concrete will continue to increase as the ASR progresses. The effect of confinement stress on ASR expansion is considered through a reduction function which is applied to equation (2):

$$
\Gamma_{c}=\left\{\begin{array}{cc}
1 & \sigma_{v} \geq 0 \\
1-\left(\sigma_{v} / \bar{\sigma}_{v}\right)^{2} & 0 \geq \sigma_{v} \geq \bar{\sigma}_{v} \\
0 & \sigma_{v} \leq \bar{\sigma}_{v}
\end{array}\right.
$$

In this equation $\sigma_{v}$ is the sum of compressive stresses in principal directions and $\bar{\sigma}_{v}$ is a limit below which ASR will be prevented. In this research, it is assumed that $\bar{\sigma}_{v}$ is equal to $-9.7 \mathrm{MPa}$.

Finally, $W_{i}\left(\sigma_{v}\right)$ is weight function in equation (2). A simple but effective technique which is proposed by Gocevski and Yildiz [22] is used. Practically it can determine the weight of ASR strain rate in each principal direction by introducing a decreasing function which links the weight of each direction to $\sigma_{v}$ volumetric stress equal to sum of the stresses in principal direction.

\subsection{Constitutive modelling of concrete}

The Plastic-damage model from Lee and Fenves [23] is used to capture concrete mechanical behaviour. This model is implemented in Abaqus [20] and a user subroutine is developed to establish a link between strain rate from ASR and damage plastic modelling. In brief, in chemo-thermo-mechanical model, effective stress is given by:

$$
\boldsymbol{\sigma}=(1-\mathrm{d}) \overline{\boldsymbol{\sigma}}=(1-d) D_{0}^{e}\left(\varepsilon-\varepsilon^{p l}-\varepsilon^{t h}-\varepsilon^{a s r}\right)
$$

where $\boldsymbol{D}_{\mathbf{0}}^{\boldsymbol{e}}$ is the initial (undamaged) constitutive tensor. The total damage $d$ of the ASR-affected concrete involved the mechanical part $\left(d_{m}\right)$ caused by external loads and the chemical part $\left(d_{a s r}\right)$ induced by ASR, and thus the damage factor is defined as:

$$
d=1-\left(1-d_{a s r}\right)\left(1-d_{m}\right)
$$

In this function $d_{m}$ is determined using tensile strength of concrete evolving with strain during the mechanical analysis. The yield function for concrete, proposed by Lee and Fenves [23] is used. The plastic strain rate is governed by non-associated plastic flow rule. In addition, the 
thermal strain is governed by the thermal coefficient $\alpha$ and the temperature differences $\Delta T$.

\subsection{Concrete deterioration due to ASR}

The deterioration of the ASR-affected concrete is timedependent, and the degradation of the elastic stiffness $\mathrm{E}$ and the tensile strength $f_{t}$ is considered based on the ASR damage factor [9]

$$
\begin{gathered}
E=E_{0}\left(1-d_{a s r}\right) \\
f_{t}=f_{t 0}\left(1-d_{a s r}\right)
\end{gathered}
$$

$E_{0}$ and $f_{t 0}$ are the initial elastic stiffness and tensile strength, respectively. During the ASR process, the swelling gels attack the concrete matrix and induce cracking of the aggregates and the surrounding cement paste. The damage of the material leads to elastic stiffness degradation. The ASR damage factor, $d_{a s r}$ may be linked with expansion strains from the experimental results as shown in Fig. 2 [24]. Furthermore, $d_{a s r}$, ASR damage factor can be determined by expansion strains based on the experimental results [9]:

$$
d_{a s r}=1-\frac{E}{E_{0}}=\frac{\max \left(\varepsilon_{i}^{a s r}\right)}{\max \left(\varepsilon_{i}^{a s r}\right)+0.003}
$$

\subsubsection{Mechanical damage}

The mesh sensitivity in the finite element modelling is prevented following the fracture energy regularization method [25], and the ultimate strain is obtained:

$$
\varepsilon_{u}=\frac{2 G_{f}}{f_{t} l_{c}}
$$

Where $G_{f}$ is the fracture energy; $l_{c}$ is the characteristic length of the element. Evolution of mechanical damage is defined by a linear softening law [26]:

$$
d_{m}=\left\{\begin{array}{cc}
0 & \kappa \leq \varepsilon_{0} \\
1-\frac{f_{t}\left(\varepsilon_{u}-\kappa\right)}{E_{0}\left(\varepsilon_{u}-\varepsilon_{0}\right)\left(\kappa-\varepsilon^{p}\right)} & \varepsilon_{0}<\kappa<\varepsilon_{u} \\
1 & \kappa \geq \varepsilon_{u}
\end{array}\right.
$$

Where $\varepsilon_{0}=f_{t} / E_{0} ; \varepsilon^{p}$ is uniaxial plastic strain and $\kappa$ is the largest converged value of strains during the mechanical analysis.

\subsection{Thermal diffusion analysis and modelling}

Temperature history is the key factor driving the ASR in massive structures such as dams [8]. Therefore, before performing mechanical analysis it is necessary to determine the temperature field in space and time. By assuming an initial condition for temperature $\theta_{0}$ at time $t_{0}$ at each integration point in the dam, the code is requested to solve the transient thermal analysis:

$$
\frac{\partial\left(\theta-\theta_{0}\right)}{\partial t}=D_{\theta} \frac{\partial^{2}\left(\theta-\theta_{0}\right)}{\partial x^{2}}
$$

where $D_{\theta}=k / C$ denotes the thermal diffusivity (i.e., conductivity $k$ divided by the volumetric heat capacity C). In order to determine the initial temperature, a steadystate analysis considering the average temperature during one cycle is performed. The results, from this analysis are used as boundary condition for transient analysis. The results from thermal analysis are used in Chemomechanical analysis through defining a predefined field temperature variation in space and time during the mechanical analysis. The user subroutine code uses the temperature value at each integration point to compute the reaction extent and consequent ASR strains.

\subsection{Numerical implementation}

ASR is a long-term process and often continues for many years. As a result, a suitable time step size must be selected to insure sufficient accuracy results and optimised computational time. The starting point of the analysis of the sequentially coupled problem of heatdiffusion and chemo-mechanical model is the solving of transient thermal analysis with initial boundary conditions. Then, mechanical analysis is performed in order to structural analysis. This requires a number of

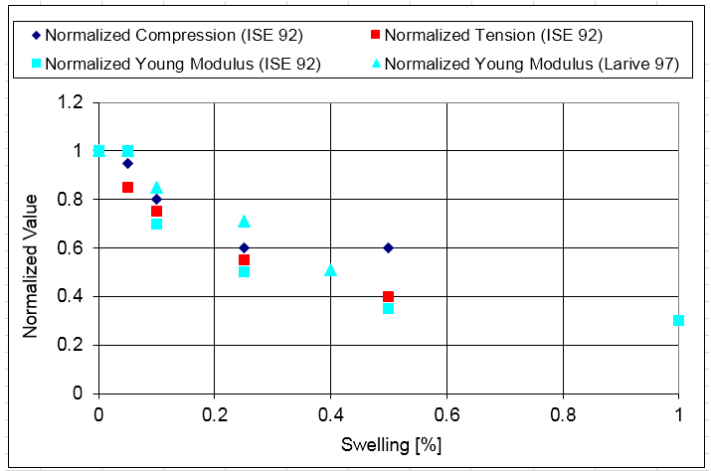

Fig. 2. Evolution of mechanical characteristic vs. ASR expansion of concrete [9]

parameters, among them: 1) the air temperature variation; 2) the spatial and temporal variation of the water temperature must be known; 3) the concrete thermal properties and 4) mechanical properties of concrete and damage-plastic parameters such as E-modulus and Poisson's ratio, compressive and tensile nonlinear stressstrain curves and damage variables in tension and compression. For thermal analysis, and the subsequent mechanical analysis, an appropriate analysis time unit or time increment, must be defined. Furthermore, the current user subroutine code is implemented in an implicit framework in which Newtown's method as a numerical technique for solving nonlinear equations is used.

\section{ASR Model verification}

In order to calibrate and validate the proposed model, references have been made to the experimental tests 
carried out on small concrete samples by Multon and Toutlemonde [18]. These tests were performed using accelerated methods. The experimental values of Young's modulus and Poisson's ratio given in Multon and Tutlemonde [18], namely $E=37300 \mathrm{MPa}$ and $v=0.22$. Fig. 3 shows the loading conditions and the 3D finite element mesh. These cylindrical specimens are $130 \mathrm{~mm}$ in diameter and $240 \mathrm{~mm}$ in height. They behave anisotropically and have different experimental axial and radial strains under the stress-free condition. These differences are mainly caused by the casting procedure [18]. This material anisotropy is not considered in the proposed model. The duration of the tests were 450 days and the temperature was $\bar{\theta}_{0}=38^{\circ} \mathrm{C}$.
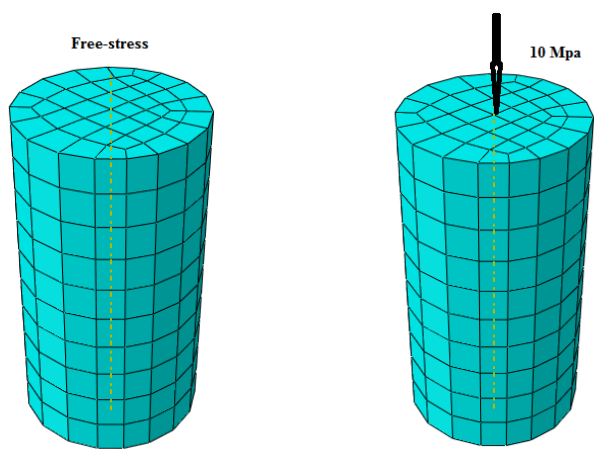

Fig. 3. Multon's samples used for model calibration in free expansion and computing axial and radial strains showing specimens for a) Free expansion b) $10 \mathrm{MPa}$ axial compression.

The model parameters of ASR kinetics are estimated by inverse analysis based on the axial and radial strains measured from stress-free experiment. These parameters are shown in Table 1.

Table 1. Parameters governing ASR volumetric expansion determined by inverse analysis at $\bar{\theta}_{0}=38^{\circ} \mathrm{C}$

\begin{tabular}{lc}
\hline Parameter & \\
$\tau_{l}[$ days $]$ & 120 \\
$\tau_{c}[$ days $]$ & 70 \\
$\beta[\%]$ & 0.28 \\
\hline
\end{tabular}

The strains from the experiment without and with axial loading condition versus time duration of the tests are shown in Figs. 4 and 5. The computed strains are compared with the experimental results. It is worth noting that the strains in axial and radial directions show different final values mainly because of the casting procedure. [The specimens are casted in axial direction].

Furthermore, Fig. 5 shows a comparison of computed strains of the samples under axial loads of $10 \mathrm{MPa}$. In this curve the strain form creep is extracted in the experimental results. The radial and axial strains are in a good agreement with the experimental results. One of the major effect that is confirmed in this test is the effect of stress state in axial direction in comparison with free stress tests. The axial strain from free-stress strain after 400 days is $0.09 \%$ while radial is $0.06 \%$ due to casting

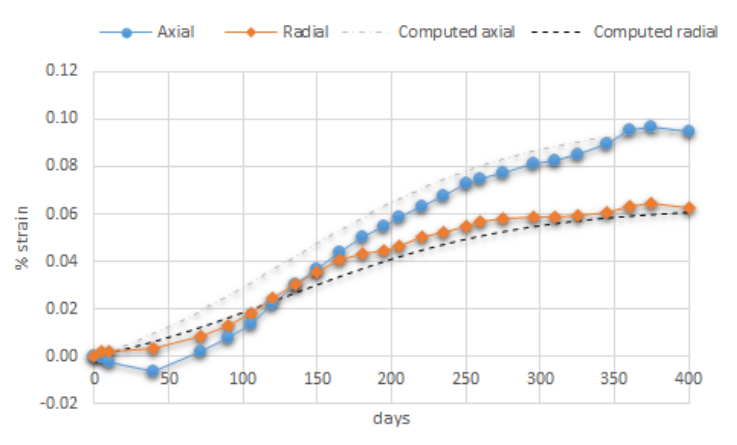

Fig. 4. Experimental [18] and computed axial and radial strains for the free expansion tests.

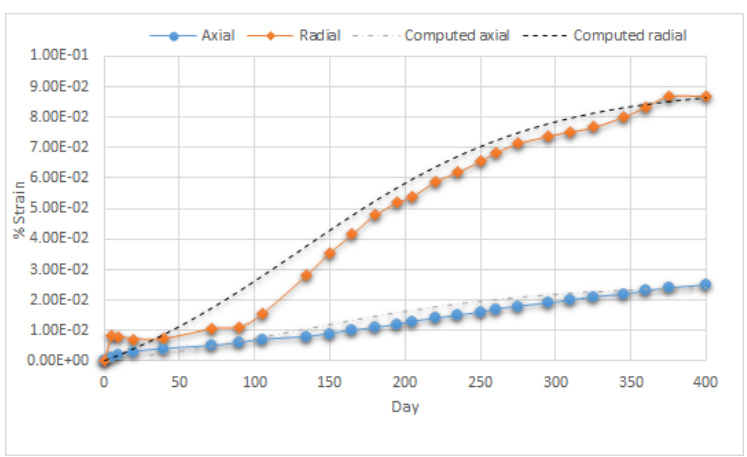

Fig. 5. Experimental [18] and computed axial and radial strains for the $10 \mathrm{MPa}$ axial compression tests.

direction. Accordingly, when $10 \mathrm{MPa}$ axial load is applied the axial strain is reduced to $0.02 \%$ while the radial strain is increased to $0.09 \%$ confirming the assumption behind volumetric strain which will be transferred to less compressed direction. It is worth noting that, in both specimens the volumetric strain is about $0.21 \%$, which is in good agreement with this assumption that ASR strain is volumetric and transfers to the less compressed direction. The volumetric strain for cylindrical samples is computed according to $\varepsilon^{v o l}=\varepsilon^{\text {axial }}+2 \varepsilon^{\text {radial }}$.

Finally, as shown in Figs. 4 and 5 the model is able to reproduce reasonably the trend of the expansion strains in all cases. 


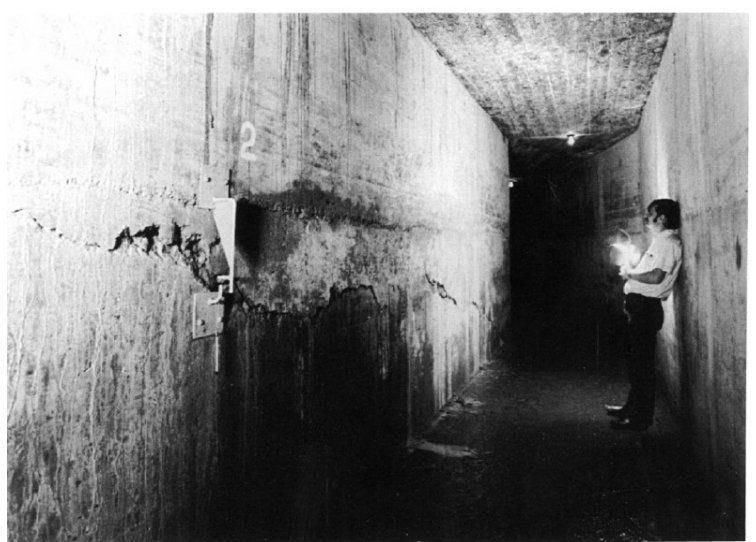

(a)

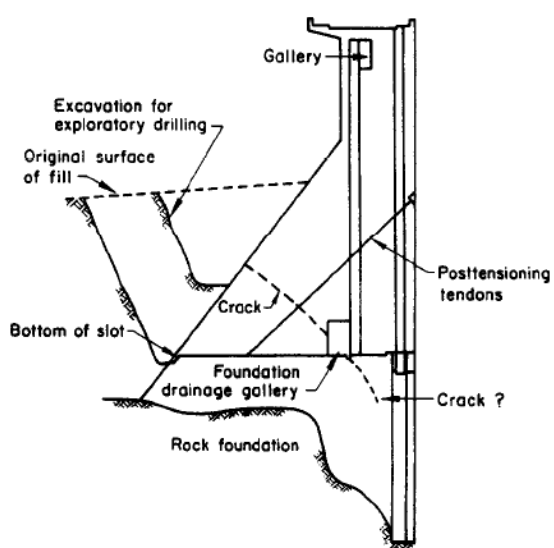

(b)

Fig. 6. Fontana dam a) crack inside gallery in left flank b) predicted crack (after Ingraffea, [21])

\section{Safety Analysis of a dam affected by ASR}

The Fontana dam, is a concrete gravity dam with $147 \mathrm{~m}$ height, $720 \mathrm{~m}$ crest length and the thickness at the basis is equal to $114 \mathrm{~m}$. Its construction was completed in 1944, and is located on the Tennessee River in North Carolina United States. Only 4 years later, in 1948, a pattern of map cracking together with upstream movements were observed in the parapets and continued extending over a number of years. Later during the structural inspection that was performed due to increasing concerns about the safety of the dam by 1972, cracking was found inside the foundation gallery near the left flank as shown in Fig. 6.a [21]. In addition, the petrographic analysis revealed some symptoms of ASR and microcracks in the dam aggregates with deposits of gels from alkali-silica reaction. Following, the chemo- thermo-damage-plastic model is used to simulate and interpret this phenomenon in the Fontana dam. The cracked section is analysed using the numerical model proposed in this study, in order to evaluate the pattern of damage generated by mechanical loads plus strains from ASR.

\subsection{Thermal analysis of Fontana dam}

Sloan and Abraham [27] have investigated three different gravity blocks of the Fontana dam. One of the main blocks that suffered from severe ASR is Block 35 with $36 \mathrm{~m}$ height. See Fig. 7. It is worth noting that the crack which was observed during the inspection is mainly located in this block. This block is near the left flank of the dam. In this analysis, the downstream filled-soil and the rock foundation are also considered in the thermal analysis as they have different conductivity and thermal-diffusion properties compared to concrete material. The thermal and mechanical properties of the dam-filled soilfoundation system are listed in Table 2. A preliminary heat-diffusion analysis is performed including the downstream filled-soil, rock foundation and concrete domains. Seasonal temperature variations for upstream and downstream of the dam incorporated the transient thermal analysis are shown in Fig. 8.

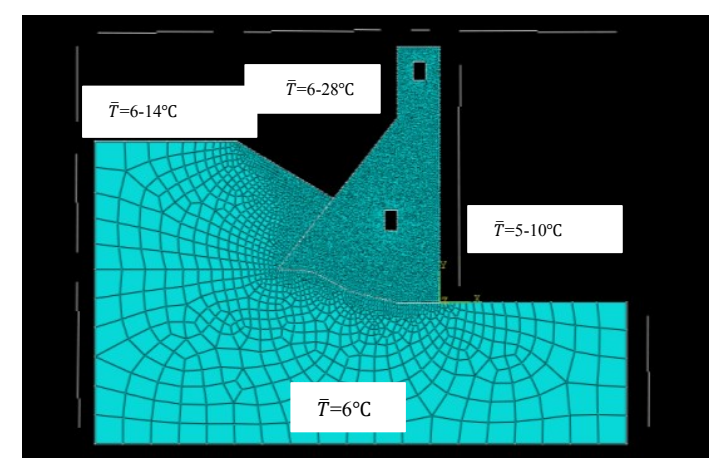

Fig. 7. FE model of Fontana dam with averaged temperatures.

In FE codes such as Abaqus [20] often the solution for the steady-periodic heat diffusion problem is not available and a time consuming transient analysis should be performed until temperature oscillations have achieved stabilization everywhere. Instead of this, according to the procedure which is mentioned in section 2.4 , the initial temperature field $\theta_{0}$ in equation (14) is sought using an average temperature during one season for upstream and downstream faces of the dam. See Fig. 7. Then this initial temperature field in the dam has been used to find seasonal temperature variations in space and time by performing a transient analysis for 10 years, using seasonal temperature data shown in Fig. 8. The initial temperature field is shown in Fig. 9 and is obtained using an average temperature for the upstream, downstream, filled-soil material and foundation boundary condition. 
Table 2. Material properties of the Fontana dam structure, foundation and filled soil

\begin{tabular}{llllllll}
\hline & $\begin{array}{l}\text { Young } \\
\text { modulus } \\
E_{0}\end{array}$ & $\begin{array}{l}\text { Poisson } \\
\text { ratio } \\
(\mathrm{GPa})\end{array}$ & $\begin{array}{l}\text { Tensile } \\
\text { strength } \\
f_{t}\end{array}$ & $\begin{array}{l}\text { Fracture } \\
\text { energy } \\
\mathrm{MPa}\end{array}$ & $\begin{array}{l}G_{t} \\
(\mathrm{~N} / \mathrm{m})\end{array}$ & $\begin{array}{l}\text { Thermal } \\
\text { conductivity } \\
k\end{array}$ \\
& & & & & $\begin{array}{l}\text { Specific } \\
\text { heat } \\
(\mathrm{W} /(\mathrm{m} \mathrm{K})\end{array}$ & $\begin{array}{l}\text { Thermal expansion } \\
(\mathrm{KJ} /(\mathrm{kg} \\
\mathrm{K})\end{array}$ & $\begin{array}{l}\begin{array}{l}\alpha \\
\left(10^{-5}\right)\end{array} \\
\text { coefficient }\end{array}$ \\
\hline Concrete & 22.0 & 0.17 & 2.1 & 200.0 & 1.75 & 0.75 & 1.0 \\
\hline Rock & 20.0 & 0.25 & - & - & 0.75 & 0.85 & 0.5 \\
\hline Filled-soil & 0.15 & 0.2 & - & - & 0.55 & 1.00 & 0.5 \\
\hline
\end{tabular}

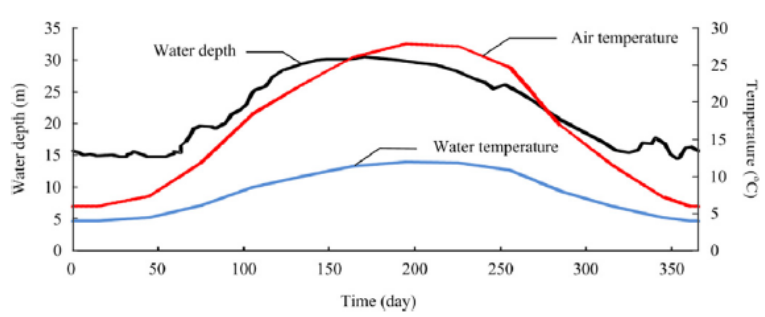

Fig. 8. Seasonal variation of air and water temperature for performing the transient thermal analysis.

\subsection{Chemo-mechanical analysis}

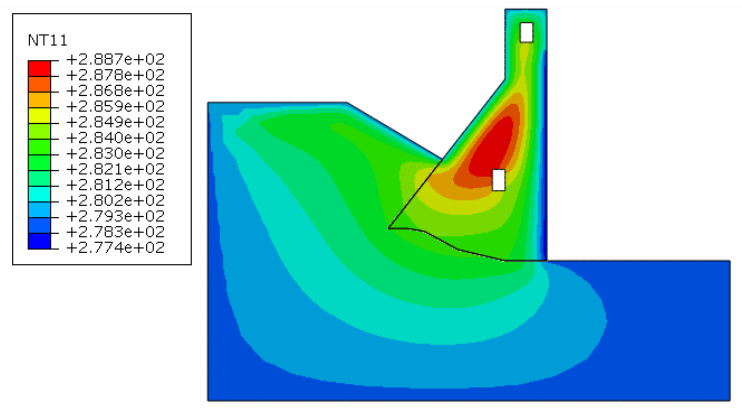

Fig. 9. Computed initial temperature field in Kelvin for the Fontana dam for a duration of 10 years.

For the mechanical analysis, about 4500 4-node quadrilateral plain strain elements of type CPE4R are used with reduced integration. Service loading namely the gravity load, seasonal temperature variations and hydrostatic pressure are applied. The damage-plastic model parameters for the concrete material are considered according to Table 2. For purpose of simplicity and reducing the cost of analysis, only the dam structure is modelled in the mechanical analysis and filled-soil and foundation are not modelled. A fixed boundary conditions is applied along the dam foundation. In this research, there are no monitoring displacements of the ASR-affected dam available to determine the ASR kinetics parameters. Hence, cracking pattern which are available in the literature is considered to identify these parameters using an inverse analysis. They are taken as follows:

\section{(1) the latency time}

$\tau_{l}\left(\theta_{0}\right)=170$ days (2) the characteristic time $\tau_{c}\left(\theta_{0}\right)=70$ days and (3) and the maximum volumetric expansion strain $\beta=0.3 \%$. Fig. 10 illustrates the development of ASR kinetics and associated tensile damage within the considered dam: spatial variation of the kinetics (first column) and tensile damage (second column) are shown at different instants along the monitored period of about 10 years. At the beginning, the temperature increases through a thin layer from downstream and gradually diffuses to the dam body. The temperature activates the kinetics of the reaction and associated strains purely from chemo physical activation of ASR. Because of the available constraints such as stress state from gravity and hydrostatics loads and also natural boundary conditions, these expansive strains increase the compressive stresses along a narrow band which gradually moves into the dam body. As a consequence of strain compatibility, the internal core of the dam must release the fracture energy through the increase in tensile strains and subsequent crack opening as shown in Fig. 10a. Furthermore, when kinetics of the reaction at this band reaches the asymptotic value, these strains exceed the tensile strength of the concrete and therefore cracks will be opened. These findings are in good agreement with observed cracks inside the gallery as shown in Fig. 6b. The ASR progresses further, and after 8 years, another crack zone appears in the low-right side of the gallery and initially propagates at a similar slope as the first cracks but soon after turns toward the rock foundation upstream of the dam. See Fig. 10b. it is worth noting that mathematically, this crack will remain stable during next phases of the analysis. This mechanism is likely due to the fact that the upstream side of the dam is not exposed to high temperature gradient and kinetics of the ASR is not activated during these years. From Fig. 10c, it can be observed that the model predicts initiation of another localized zone with crack opening in the downstream face of the dam. This crack propagates toward the internal gallery and finally intersects with the older crack. One can interpret that after 8 years, the ASR concentration reaches mainly out to the gallery and causes high compressive stresses inside the dam. Irreversible plastic strains and cracks in the downstream face are basically due to strain compatibility with high constraints stresses around the gallery.

In order to evaluate the global behaviour of the dam structure, it is also important to assess the strain rate and displacements of the dam at the crest level. Figs. 11 and 

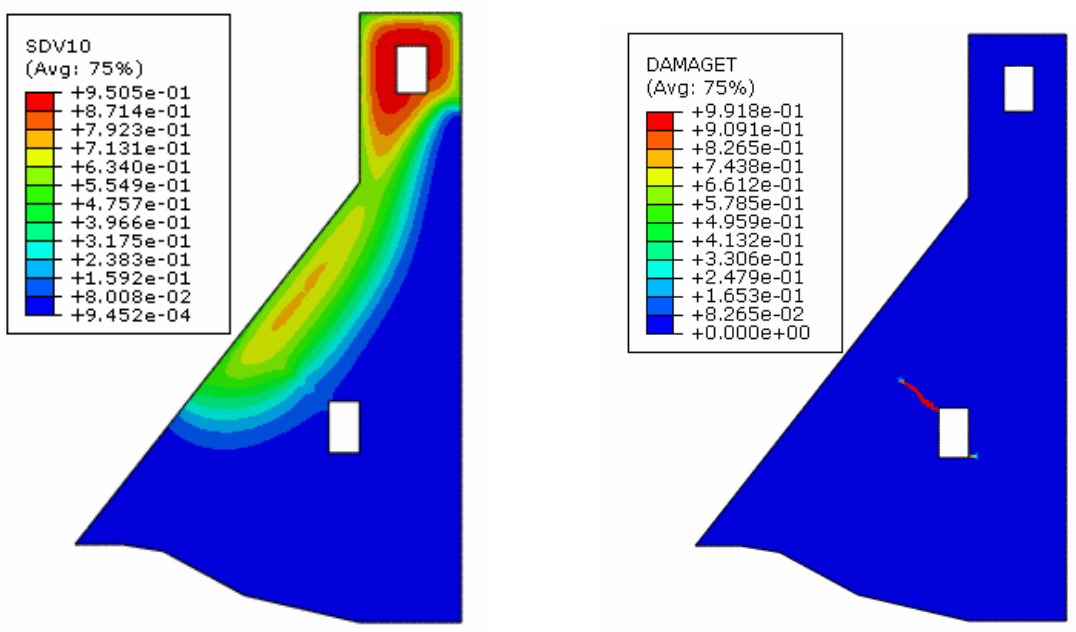

a)
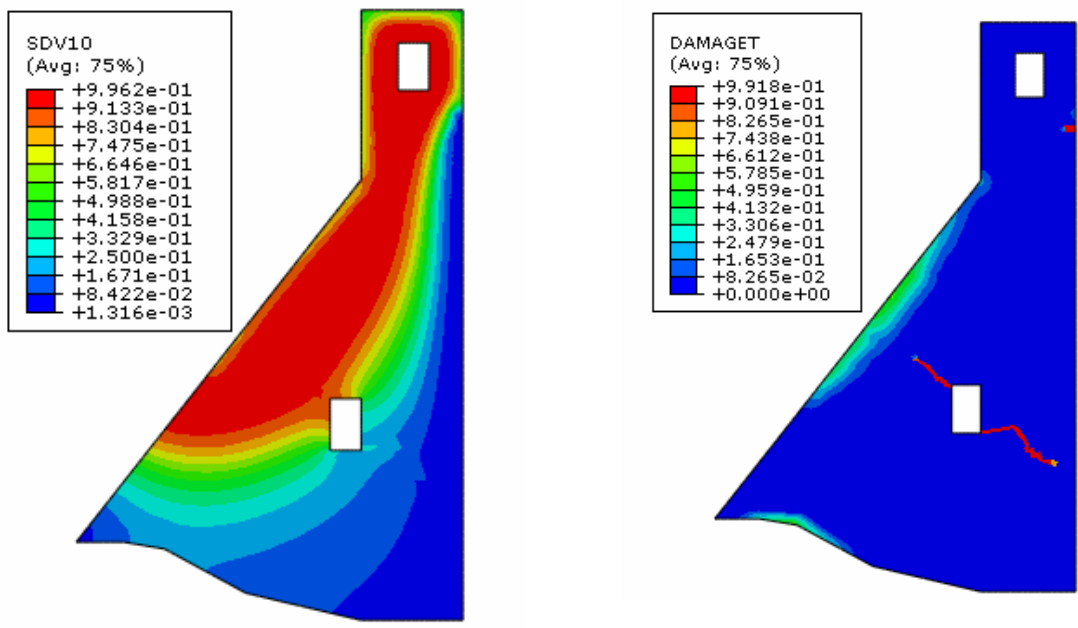

b)
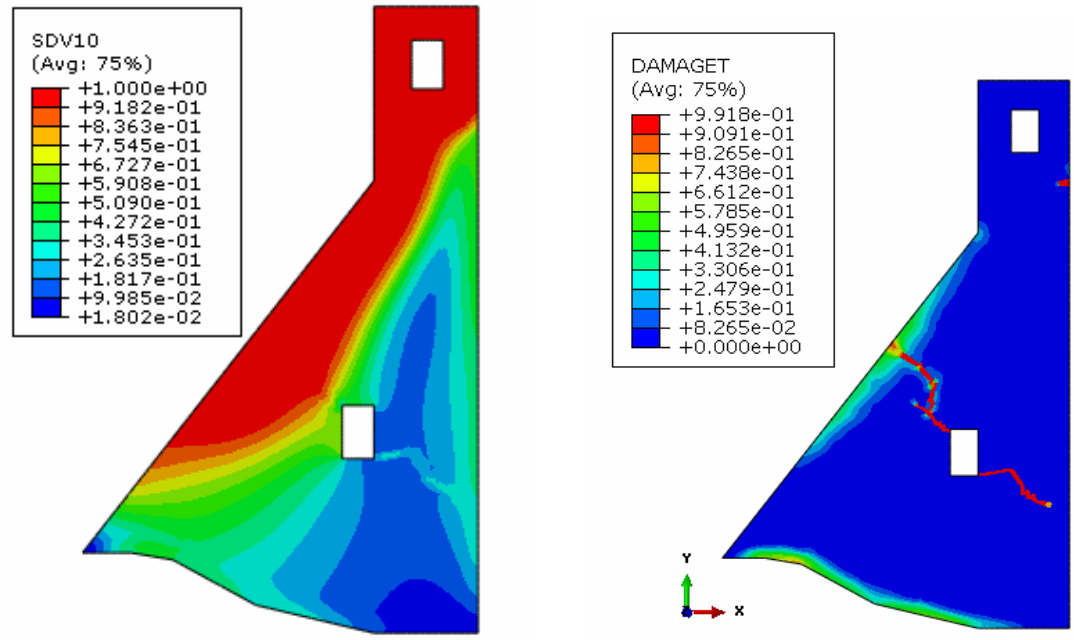

c)

Fig. 10. Tensile damage and reaction extent. a) after 4 years b)after 8 years c) after 10 years 


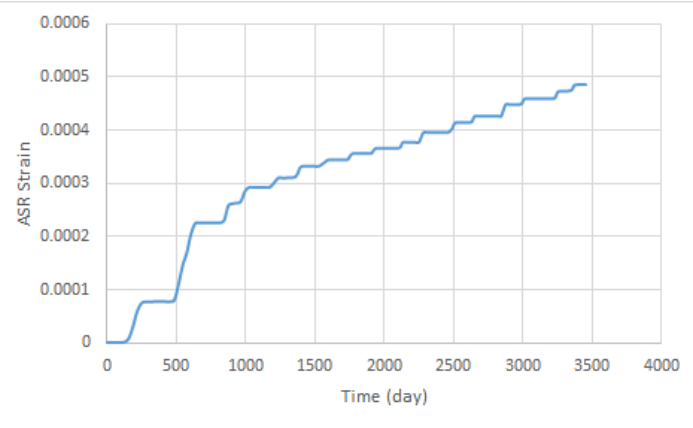

Fig. 11. Horizontal strain vs. time at crest

12 illustrate the strain rate, horizontal and vertical displacements. From these figures it is clear that the dam crest has experienced a constant crest displacement toward downstream about $4.5 \mathrm{~mm} /$ year.

\section{Rehabilitation methodology}

During the two last decades research has been carried out in the field, resulting in practical advancements in relevant areas of expansive chemical reactions and in particular, dams suffering from ASR. An increasing number of affected dam cases have been documented, whereas in some of them rehabilitation and repair provisions were implemented and a small number of them were decommissioned [28]. These studies reveal that the ASR-related risk to a dam is specific to the dam type, and it may not be possible to provide a unified prescription for all dams. A variety of parameters such as rate and magnitude of the expansion, long-term viscoelastic behaviour such as creep and relaxation, type of dam, equipment and geological configuration could determine the appropriateness and effectiveness of remedial actions.

In this research, the proposed model is not used to model the rehabilitation interventions for the dam, but is intended to demonstrate the applicability of the model and show a strategy which is applicable to rehabilitation, repair and remedial action of concrete dams affected by ASR. The strategies and opinions expressed here, are those of the authors based on their interpretation of the current research and literature review.

According to the numerical analysis performed in previous sections and through a comprehensive literature review, range of manifestation, identified issues and impacts resulting from ASR expansion are categorized in distinguished zones for a generic gravity dam and are shown in Fig. 13. In general, these zones are Zone I, where spillway and measuring instruments are installed at the crest, Zone II, where galleries are located, Zone III is the drainage system, piping and foundation, and zone IV is the downstream face of the dam.

In Zone I, mathematically, there is not any natural boundary condition against ASR expansion and often strain from ASR leads to vertical and horizontal movements during the service life of the structure. Microcracks are observed during gallery inspection and numerical analysis supports this finding. If spillways are

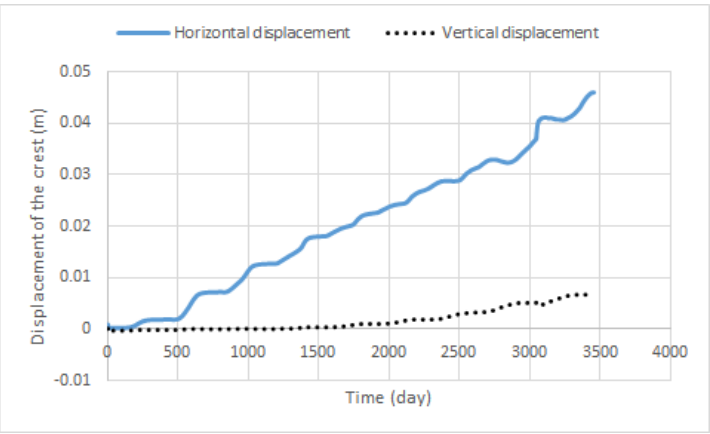

Fig. 12. Crest displacement vs. time at crest

equipped with the sluice gates, possible misalignments of the gates and pendulums are expected. The Kariba dam in the Zambezi river is a representative case in this category. In this arch dam, the concrete expansion is affecting the spillway sluices geometry and has damaged the upstream stoplog rollerpath. The remedial measures for this dam include refurbishment of the stoplog rollerpath and installation of the new upstream set of stopbeams in combination with an emergency gate [29].

Zone II, represents the major body of the dam and most of the inspection galleries and penstock are located in this area. In this zone, cracks along gallery wall and potential leakage from upstream through these cracks, penstock equipment misalignments are detected. The Fontana dam, which is evaluated in this research is one the example of this zone. Fig. $6 \mathrm{~b}$ shows the rehabilitation of the Fontana dam using post-tension tendons. The effectiveness of this remedial action was evidenced by Ingraffea some years later [21]. Foundation and drainage systems are critical parts of the dam and are mainly located in Zone III. The concerns in this zone are mainly vulnerability of these parts to increase the pore pressure from right or left flanks or abutments, uplift from upstream heel and stress concentration at toe of the dam due to large constraints and slope instability of the foundation as a result of liquefaction. The ASR may lead to worsening all of these unfavourable mechanisms. Finally, in Zone IV, the downstream face is exposed to the temperature gradient is a potential region of the dam to initiate the alkali silica reaction. Here, this can also lead to opening of the horizontal and vertical construction joints and failure of the watertightness elements in this zone.

The strategies for repair and remedial actions range from short-term actions including repair of the key items such as: spillway gates, post tensioned anchors and power generation equipment to long-term management of ASR such as reinforcing and slot cutting of large mass concrete structures. In summary, the suitable strategies for each zone are listed in Table 3. 


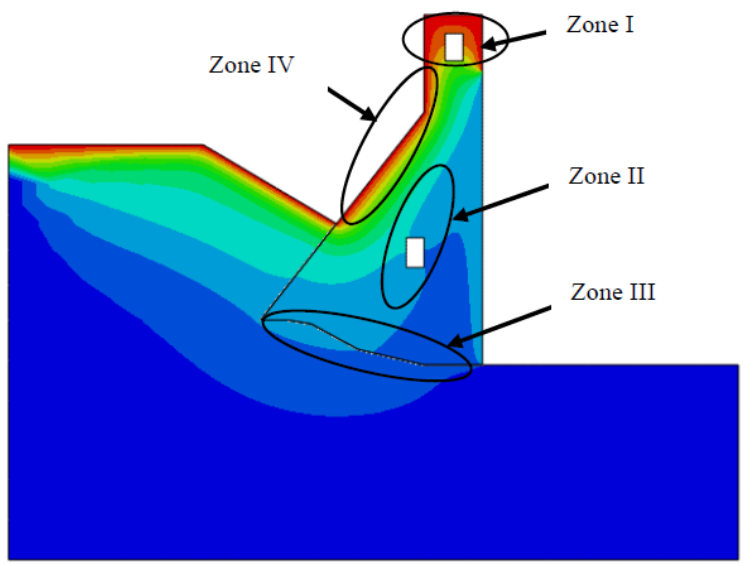

Fig 13. Recognised damage zones in a typical gravity dam

\section{Conclusions}

In this paper a chemo-thermo-plastic-damage model is presented, for analysis and prediction of the multi-scale behaviour of concrete structures such as dams. At material level, the reduction of ASR expansion under multi-axial confinement (3D stress state) has been clearly demonstrated. This model is intended to facilitate the prediction of the expansion rate from ASR during the service life of the structure and as a tool to investigate structural performance and possible instabilities such as irreversible displacement and cracks.

The model has been implemented in an Abaqus user subroutine which is a commercial finite element code. In this proposed model, the heat-diffusion analysis is decoupled from mechanical analysis, and the output from preliminary thermal analysis is used as a predefined field for the next analysis including ASR and mechanical damage. The model is validated at the material scale on the basis of the recently published paper on experimental modelling of ASR considering the triaxial stress state [16]. At structural level, a finite element model is constructed for a gravity dam suffering from ASR. The reaction extent and damage parameters are presented and the results are compared and interpreted with realistic dam behaviour.

One of the main features of the presented model is inclusion of the material stiffness degradation with ASR evolving during the time. Considering this feature in the model, it may result in better prediction of structural strains and displacements during the service life of the structure.

Finally, in this research the effects of elastic, plastic and thermal strains are considered in chemo-mechanical modelling of a dam structure affected by ASR. Since ASR develops during the service life of the dams, other long term effects such as creep, relaxation and shrinkage should be properly described in future works. Also, FE modelling of a rehabilitated dam to assess the effectiveness of the remedial actions is one of the other topics for future research.
Table 3. Rehabilitation and remedial strategies for a dam affected by ASR in terms of different manifestation of ASR

\begin{tabular}{|c|c|c|c|c|c|}
\hline time & $\begin{array}{l}\text { Remedial } \\
\text { action }\end{array}$ & $\begin{array}{c}\text { Zone } \\
\text { I }\end{array}$ & $\begin{array}{c}\text { Zone } \\
\text { II }\end{array}$ & $\begin{array}{c}\text { Zone } \\
\text { III }\end{array}$ & $\begin{array}{c}\text { Zone } \\
\text { IV }\end{array}$ \\
\hline \multirow{3}{*}{ 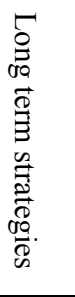 } & Slot cut & $*$ & & & $*$ \\
\hline & $\begin{array}{l}\text { Improve } \\
\text { monitoring } \\
\text { system and } \\
\text { instrumentation }\end{array}$ & $*$ & $*$ & $*$ & $*$ \\
\hline & Post tensioning & $*$ & $*$ & & * \\
\hline \multirow{6}{*}{ 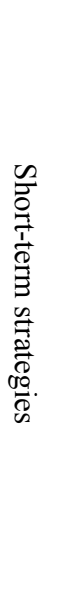 } & $\begin{array}{l}\text { Grouting of } \\
\text { internal cracks }\end{array}$ & $*$ & $*$ & $*$ & * \\
\hline & $\begin{array}{l}\text { Reinforcement of } \\
\text { the abutment of } \\
\text { the dam }\end{array}$ & & & $*$ & \\
\hline & $\begin{array}{l}\text { Grouting of } \\
\text { construction joint }\end{array}$ & & $*$ & & $*$ \\
\hline & $\begin{array}{l}\text { FRC, USC,HSCC } \\
\text { Geomembrane }\end{array}$ & $*$ & & & $*$ \\
\hline & $\begin{array}{l}\text { Installation of } \\
\text { watertightness }\end{array}$ & $*$ & & & $*$ \\
\hline & Ice cooling & $*$ & & & * \\
\hline
\end{tabular}

The first author acknowledges the research scholarship received from the Institute of Structural Engineering (ISE) at Stellenbosch University to conduct the research as a part of his $\mathrm{PhD}$ programme.

\section{References}

1. T. E. Stanton, Expansion of concrete through reaction between cement and aggregate., Proc. Amer. Soc. Civ. Eng., 66: 1781-1811(1940).

2. Fulton, Concrete technology, Cem. Con. Inst., Midrand, South Africa. (2009).

3. G. Blight, Mark. G. Alexander, Alkali-Aggregate Reaction and Structural Damage to Concrete. Taylor \& Francis. (2008).

4. M. S. Pourbehi, G.P.A.G. van Zijl, J.A.v.B. Strasheim, Numerical modelling of ASR in concrete dams, $P h D$ Research proposal, Stellenbosch University, South Africa (2015)

5. J. Newman, B. S. Choo, Adv. Con. Tech., ButterworthHeinemann, Elsevier (2003).

6. F. Glasser, Chemistry of the alkali-aggregate reaction. In R. Swamy, editor, The Alkali-silica Reaction in Concrete, pages 30 Van Nostrand Reinhold, New York. (1992)

7. R. G. Chalrlwood, S. V. Solymar, D. D. Curtis, A review of alkali aggregate reactions in hydroelectric plants and dams, proceedings of the International Conference of Alkali-Aggregate Reaction in Hydroelectric Plants and Dams, Fed., Canada, 129 (1992) 
8. F. Ulm, O. Coussy, L. Kefei, C. Larive, ThermoChemo-Mechanics of ASR Expansion in Concrete Structures, J. Eng. Mech. V. 126, No. 3, (2000)

9. B. Capra, A. Sellier, Orthotropic Modelling of AlkaliAggregate Reaction in Concrete Structures: Num. Sim. Mech. Mat., V. 35, 817-830. (2003)

10. V. Saouma L. Perotti, Constitutive model for alkali aggregate reactions. ACI Mater. J. ;103 (2006)

11.Z. P. Bažant, and A. Steffens, Mathematical model for kinetics of alkali-silica reaction in concrete. Cem. Con. Res., 30:419-428. (2000)

12. L., Dormieux, D. Kondo, F. J., Ulm, Microporo Mechanics, John Wiley \& Sons Ltd., England. (2006)

13. C. Dunant, K. Scrivener, Micro-mechanical modelling of alkali-silicareaction-induced degradation using the AMIE framework. Cem. Con. Res., 40:517-525. (2010)

14. I. Comby-Peyrot, F.Bernard, P.Bouchard, F.Bay, and E. Garcia-Diaz, Development and validation of a $3 \mathrm{~d}$ computational tool to describe concrete behaviour at mesoscale. Application to the alkali-silica reaction. Comp. Mat. Sci., 46(4):1163-1177. (2009).

15. C. Larive, Apports Combin'es de l'Experimentation et de la Modélisation à la Comprehension del'AlcaliRéaction et de ses Effets Mécaniques, PhD thesis, Paris. (1998)

16. J. Liaudat, I. Carol C. Lopez V. Saouma, ASR expansion in concrete under triaxial confinement, Cem. Con. Com. 86 (2018)

17. A. B. Giorla, K. L. Scrivener, C.F. Dunant, Influence of visco-elasticity on the stress development induced by alkali-silica reaction, Cem. Concr. Res. 70 (2015)
18. S. Multon, F. Toutlemonde, Effect of applied stresses on alkali-silica reaction-induced expansions. Cem. Con. Res. 36 912-20. (2006)

19. S. Mohamad. Aluad, Durability of concrete under combined action: Mechanical load and ASR, PhD thesis, Stellenbosch University, SA, (2016)

20. Abaqus, Release 2016. Theory and User's manuals. Dassault systems, USA, (2016)

21. A. R. Ingraffea, Case studies of simulation of fracture in concrete dams. Eng. Frac. Mech., 35 (1990)

22. V. Govevski E. Yildiz, Numerical analysis of aar affected structures with slot-cuts, DSC, Wiley (2017)

23. Lee J, Fenves, LG. Plastic damage model for cyclic loading of concrete structures. J. Eng. Mech. ASCE: 124 (1998)

24. Inst. of Struc. Eng., Structural effects of alkali-silica reaction, Technical guidance on the appraisal of existing structures. Technical report, Report of an ISE task group, (1992)

25. Z. Bažant, B. H. Oh, Crack band theory for fracture of concrete. Mat. and Struc., 16:155-177, (1983)

26. J. Pan, Y. Xu, F. Jin, C. Zhang, A unified approach for long term behaviour and seismic response of AARaffected concrete dams, Soil Dyn. Earth. Eng., 63: 193-202. (2014)

27. R. C. Sloan and T. J. Abraham, TVA cuts deep slot in dam ends cracking problems. Civ. Eng. 48, (1978).

28. A. Sellier, E. Grimmal, S. Multon and E. Bourfarot, Swelling concrete in dams and hydraulics structures, DSC, Wiley, (2017)

29.Z. S, Mhalanga, Rehabilitation of the spillway upstream control facility and reshaping of the plunge pool, SANCOLD conf., Jburg, South Africa (2014). 